\title{
Influence of microstructural discontinuities on the behaviour of long cracks in the VHCF regime for the aluminium alloys EN AW 6082 and EN AW 5083
}

\author{
Tina Kirsten ${ }^{1, *}$, Fatih Bülbül ${ }^{2}$, Marcel Wicke ${ }^{3}$, Hans-Jürgen Christ ${ }^{2}$, Angelika Brückner-Foit ${ }^{3}$, and Martina \\ Zimmermann $^{1}$ \\ ${ }^{1}$ Technical University of Dresden, Institute for Materials Science, 01069 Dresden, Germany \\ ${ }^{2}$ University of Siegen, Institute for Materials Engineering, 57068 Siegen, Germany \\ ${ }^{3}$ University of Kassel, Institute for Materials Engineering, 34125 Kassel, Germany
}

\begin{abstract}
In the present study two different aluminium alloys, the precipitation hardening alloy EN AW 6082 (peak-aged and overaged) and the work-hardening alloy EN AW 5083 (soft annealed) were examined. Fatigue cracks were initiated by means of a focused ion beam notch and a longdistance microscope was used for in-situ observation of the crack growth behaviour. The crack growth was investigated at constant stress intensity factors near the threshold regime. During the insitu investigation a change in crack growth velocity was detected. It could be observed that the barrier function of grain boundaries and primary precipitations are the major reason for crack growth retardation despite the fact that the crack is in the long crack growth range. The microstructural influence becomes more important with decreasing $\Delta \mathrm{K}$ values, meanwhile the average crack growth rate decreases simultaneously. Experimental results have shown that the Febased precipitates are influencing the crack growth rate for both aluminium alloys. Meanwhile, grain boundaries are causing a deceleration of the crack growth rate primarily in case of the work hardened aluminium alloy. This is assumed to be the reason for the smaller average crack growth rate in EN AW 5083 compared to that observed for the precipitation hardening alloy while applying comparable $\Delta \mathrm{K}$ values.
\end{abstract}

\section{Introduction}

In previous studies the fatigue behaviour of metallic materials at very high number of load cycles $\left(\mathrm{N}>10^{7}\right.$, VHCF) was thoroughly investigated (for example [1]). It has been shown that fatigue cracks can propagate even at amplitudes well below the classical fatigue limit (for example [2]). As for the life determining characteristics, these studies mainly focus on the crack initiation phase [3]. The crack growth phase at VHCF relevant low stress amplitudes is not as intensively investigated as of yet. The otherwise time and cost intensive testing in the VHCF regime can be addressed by using high frequency testing systems [4], such as the ultrasonic fatigue testing system used in this research.

The aim of the present work is to analyse the fatigue crack growth behaviour of two commercially available aluminium alloys (EN AW 6082 and EN AW 5083) in the near-threshold regime at constant stress intensity factors $(\Delta \mathrm{K})$ using an ultrasonic fatigue testing system in order to gain insight into the barrier function of microstructural inhomogeneities such as large precipitates or grain boundaries. The threshold $\Delta \mathrm{K}_{\mathrm{th}}$ is determined experimentally using ASTM E 647 [5]. This implies using the load-shedding method, in which the threshold is reached by continuously decreasing the applied load amplitude until the crack growth rate is less than $10^{-11} \mathrm{~m} /$ cycle. Previous studies could show that crack initiation for aluminium alloys may occur at subsurface regions in the VHCF regime [6]. In order to analyse the early crack growth behaviour it is necessary to add an artificial crack initiation site to the sample surface rather than rely on inherent crack initiation. Hence, a micronotch was inserted by means of focused ion beam technology (FIB).

\section{Material and Testing}

In this study the aluminium alloys EN AW 6082 and EN AW 5083 were investigated. Table 1 shows the chemical composition for both alloys.

EN AW 6082 is a precipitation-hardening alloy, whose microstructure is defined by a rolling texture with elongated grains of a length of $\sim 500 \mu \mathrm{m}$ and a width of $\sim 50 \mu \mathrm{m}$ (see Figure 1a). The material is characterized by primary $\left(\mathrm{Mg}_{2} \mathrm{Si}, \mathrm{Al}(\mathrm{Si}, \mathrm{Mn}, \mathrm{Fe})\right)$ and secondary $\left(\mathrm{Mg}_{2} \mathrm{Si}\right)$ precipitates (see Figure 2). The alloy was examined in peak-aged (pa) and overaged (oa) condition. The heat treatment is given in Table 2 .

EN AW 5083 is a work hardening alloy, which was investigated in the soft-annealed condition with nearly globular grains (around 40-50 $\mu \mathrm{m}$, see Figure 1b). Besides the grain morphology the microstructure is

Corresponding author: tina.kirsten@tu-dresden.de 
defined by the primary precipitates of type $\mathrm{Mg}_{2} \mathrm{Si}$ and $\mathrm{Al}_{6}(\mathrm{Mn}, \mathrm{Fe})$. Due to soft-annealing any influence of initial work hardening can be ruled out.

Table 1. Chemical composition (in weight \%) of the materials investigated according to Bikar-Aluminium (EN AW 6082) and Hydro (EN AW 5083).

\begin{tabular}{|c|c|c|}
\hline & EN AW 6082 & EN AW 5083 \\
\hline $\mathrm{Mg}$ & $0.6-1.2$ & $4.0-4.49$ \\
\hline $\mathrm{Mn}$ & $0.4-1.0$ & $0.4-1.0$ \\
\hline $\mathrm{Si}$ & $0.7-1.3$ & 0.4 \\
\hline $\mathrm{Fe}$ & 0.5 & 0.4 \\
\hline $\mathrm{Zn}$ & 0.2 & 0.25 \\
\hline $\mathrm{Cu}$ & 0.1 & 0.1 \\
\hline $\mathrm{Cr}$ & 0.25 & $0.05-0.25$ \\
\hline $\mathrm{Ti}$ & 0.1 & 0.15 \\
\hline $\mathrm{Al}$ & Bal. & Bal. \\
\hline
\end{tabular}

Table 2. Precipitation hardening heat treatment.

\begin{tabular}{|c|c|c|}
\hline & pa & oa \\
\hline Homogenization & $540^{\circ} \mathrm{C}, 1 \mathrm{~h}$ & $540^{\circ} \mathrm{C}, 1 \mathrm{~h}$ \\
\hline Quenching & Water & Water \\
\hline Annealing & $200^{\circ} \mathrm{C}, 4 \mathrm{~h}$ & $200^{\circ} \mathrm{C}, 24 \mathrm{~h}$ \\
\hline
\end{tabular}
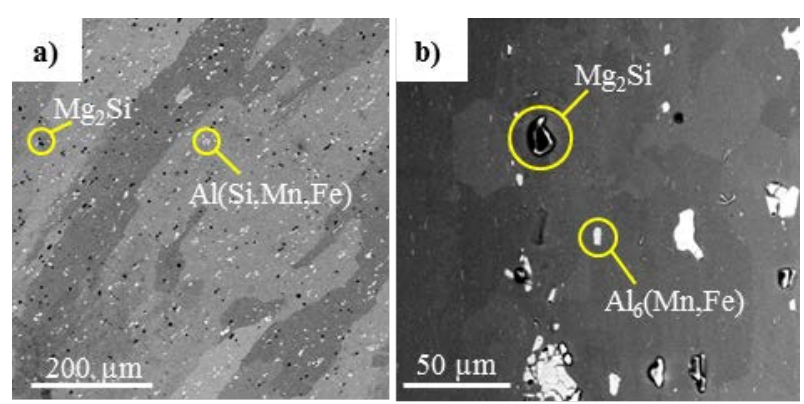

Figure 1. Microstructure with primary precipitates of the investigated material a) EN AW 6082 b) EN AW 5083.
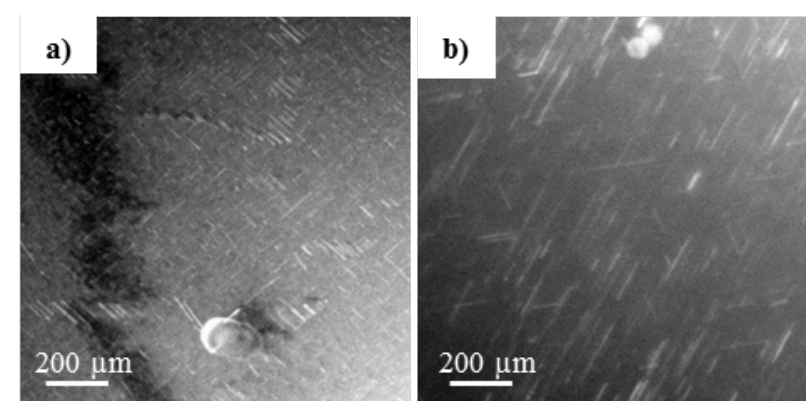

Figure 2. Transmission electron micrographs of the secondary precipitates of alloy EN AW 6082 in a) peak-aged and b) overaged condition.

The fatigue crack growth tests were performed using an ultrasonic fatigue testing system operating at a resonance frequency of about $20 \mathrm{kHz}$ and a load ratio of
$\mathrm{R}=-1$. In front of the ultrasonic fatigue testing system, a long-distance microscope is installed, which has a maximum magnification of $750 \mathrm{x}$ and was provided by the workgroup of Prof. Brückner-Foit from the University of Kassel. The testing area is shown in Figure 3a. The samples are hour-glass shaped with a shallow notch in the centre area. Furthermore, there is a micro notch inserted on the ground of the shallow notch by means of focused ion beam technology. It acts as a definite crack initiation site for optical crack growth investigations (see Figure 3b).

The crack growth tests were carried out in pulsepause mode to prevent the samples from heating. At first the thresholds for long crack growth were experimentally defined by means of the load shedding method. The threshold was assumed, when crack propagation was no longer measurable, which is defined as a drop of the crack growth rate below $10^{-11} \mathrm{~m} /$ cycle. Subsequent tests were performed at a quasi-constant stress intensity factor $\Delta \mathrm{K}$. This was achieved by repeatedly adapting the load amplitude $\Delta \sigma / 2$ according to the optical measurements of the crack growth throughout the entire test.

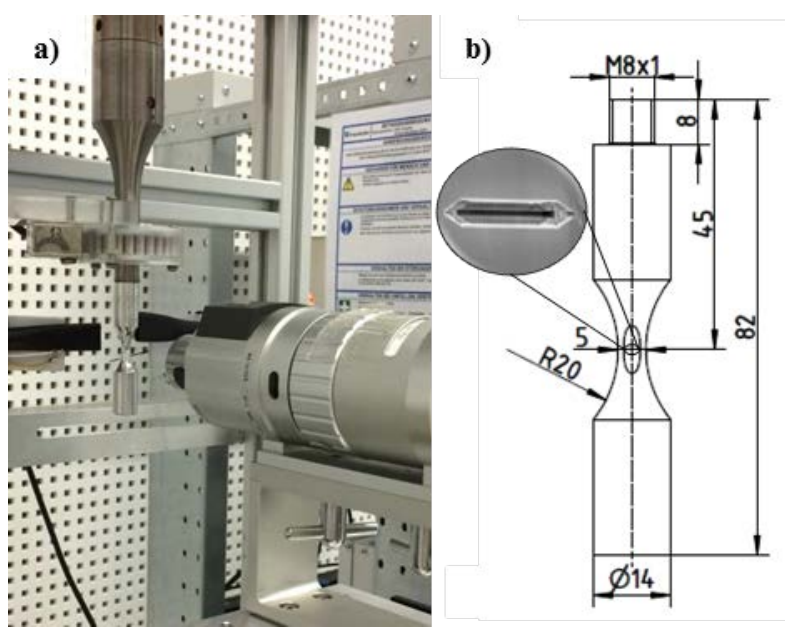

Figure 3. a) Ultrasonic fatigue testing system (BOKU Vienna) with long-distance microscope in front (Hirox) b) sample geometry with shallow notch and SEM image of FIB notch.

\section{Experimental Results and Discussion}

\subsection{Threshold for long fatigue crack growth}

First experiments were performed to determine the threshold for long fatigue crack growth. The results are shown in Table 3. It can be seen that the peak-aged material has a superior resistance against crack growth compared to the overaged material, which results in a higher threshold value $\Delta \mathrm{K}_{\mathrm{th}}$. This is in accordance to the literature [7]. Furthermore Wicke et al. observed a similar tendency while measuring the threshold values at $\mathrm{R}=0.1$ for the same material [8]. The highest threshold however was measured for the work hardening alloy.

Applying the load-shedding method to define the long crack threshold can result in threshold values that are slightly overestimated since likely crack closure 
effects may become effective. However, because of the sample geometry restrictions due to the ultrasonic fatigue testing other methods, such as the method proposed by Tabernig and Pippan [9], were not applicable. Comparing the results presented in this manuscript with those of Stein et al., who applied the aforementioned method on the same material, it can be seen that the threshold values are in a similar range [10].

Table 3. Measured threshold values $\Delta \mathrm{K}_{\mathrm{th}}$ for the materials and heat treatment conditions investigated.

\begin{tabular}{|c|c|c|c|}
\hline & $\begin{array}{c}\text { EN AW } \\
\mathbf{6 0 8 2} \mathbf{~ p a}\end{array}$ & $\begin{array}{c}\text { EN AW } \\
\mathbf{6 0 8 2} \mathbf{~ o a}\end{array}$ & $\begin{array}{c}\text { EN AW } \\
\mathbf{5 0 8 3}\end{array}$ \\
\hline $\begin{array}{c}\Delta \mathrm{K}_{\mathrm{th}, 1} \\
{[\mathrm{MPa} \sqrt{\mathrm{m}}]}\end{array}$ & 1.39 & 1.31 & 1.45 \\
\hline $\begin{array}{c}\Delta \mathrm{K}_{\mathrm{th}, 2} \\
{[\mathrm{MPa} \sqrt{\mathrm{m}}]}\end{array}$ & 1.44 & 1.35 & 1.56 \\
\hline $\begin{array}{c}\Delta \mathrm{K}_{\mathrm{th}, 3} \\
{[\mathrm{MPa} \sqrt{\mathrm{m}}]}\end{array}$ & 1.56 & 1.38 & 1.69 \\
\hline$\varnothing[\mathrm{MPa} \sqrt{\mathrm{m}}]$ & $\mathbf{1 . 4 6}$ & $\mathbf{1 . 3 5}$ & $\mathbf{1 . 5 7}$ \\
\hline
\end{tabular}

\subsection{Fatigue crack growth at constant $\Delta \mathrm{K}$}

In order to investigate the microstructural influence on the crack propagation in the VHCF regime, tests were carried out under constant $\Delta \mathrm{K}$ values. The influence of the microstructure can be detected by changes of the crack growth rate $(\mathrm{da} / \mathrm{dN})$ over the crack length (a). Because of the used FIB notch, there are always two crack fronts, which are measured (left and right from the notch). If not otherwise specified, the following curves are considering always the overall fatigue crack growth on both sides of the FIB notch. Figure 4 shows the da/dN vs. a curves for all materials/heat treatment conditions investigated at $\Delta \mathrm{K}$ values, which are less than $10 \%$ above the determined average threshold values.

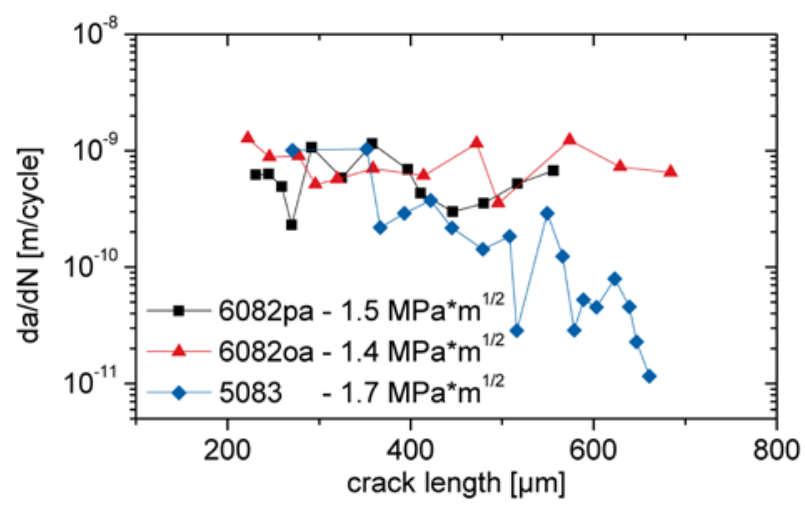

Figure 4. Crack growth rate vs. crack length for the materials/ heat treatment conditions investigated at constant $\Delta \mathrm{K}$ values.

It can be seen that there is no great difference between the fatigue crack growth behaviour of the two heat treatment conditions of alloy EN AW 6082. Both curves are showing variations of the crack growth rate. It decreases at some points, which can be attributed to the microstructure (for further details see section 3.3). Compared to the precipitation-hardening aluminium alloy, the average crack propagation rate in EN AW 5083 is lower. Furthermore, a decrease of the crack growth rate can be observed throughout the entire test finally resulting in a rate below $10^{-11} \mathrm{~m} /$ cycle. According to Zerbst et al. the minimum crack growth rate is associated with the lattice arrangement of the atoms and the minimum displacement provided by the Burgers vector, which for aluminium is $2.86^{*} 10^{-10} \mathrm{~m} \mathrm{[11]}$. For this reason, the crack growth must have been stopped in between two measurements of the crack length, which is supposed to be caused by some microstructural barriers. The true crack growth rate should then be above the determined lower limit. A continuous crack growth seems not possible close to the threshold.

Similar tendencies can be detected for higher $\Delta K$ values (see Figure 5). The average crack propagation rate for both heat treatment conditions does not differ significantly, but in comparison the average crack growth rate for alloy EN AW 5083 is again well below that of EN AW 6082. Since the stress intensity factors for the curves given in Fig. 5 are comparable and the primary precipitates present in both alloys seem to have a stronger influence on the course of the crack growth curve (as will be shown later) than the overall growth rate, there must be another reason for the pronounced difference in growth rate. Hence, it is assumed that the smaller average grain size of alloy EN AW 5083 is associated with the lower crack propagation rates. In addition, a likely influence of a different size of the plastic zone formed at the crack tip has to be taken into consideration as well.

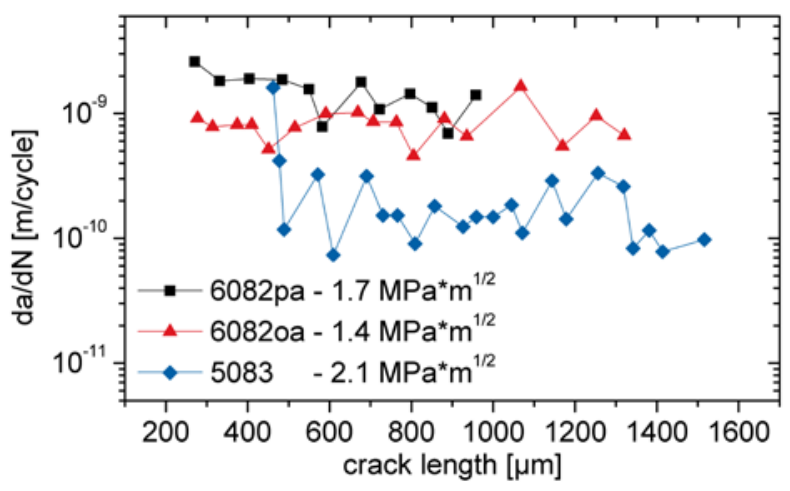

Figure 5. Crack growth rates vs. crack length at constant $\Delta \mathrm{K}$ values for the alloys EN AW 5083 and EN AW 6082.

Figure 6 represents the da/dN vs. a curves for various $\triangle \mathrm{K}$ values for the overaged condition of alloy EN AW 6082. There are two main characteristics visible. On the one hand the average crack growth rate increases with increasing $\Delta \mathrm{K}$ value, while on the other hand the variations of the crack growth rate diminish at the same time. As a consequence, it can be assumed that the influence of the microstructure becomes smaller with increasing $\Delta \mathrm{K}$ and is nearly neglectable at $2.2 \mathrm{MPa}{ }_{\mathrm{m}}$, which is $63 \%$ above the threshold but still a very low crack growth rate. 

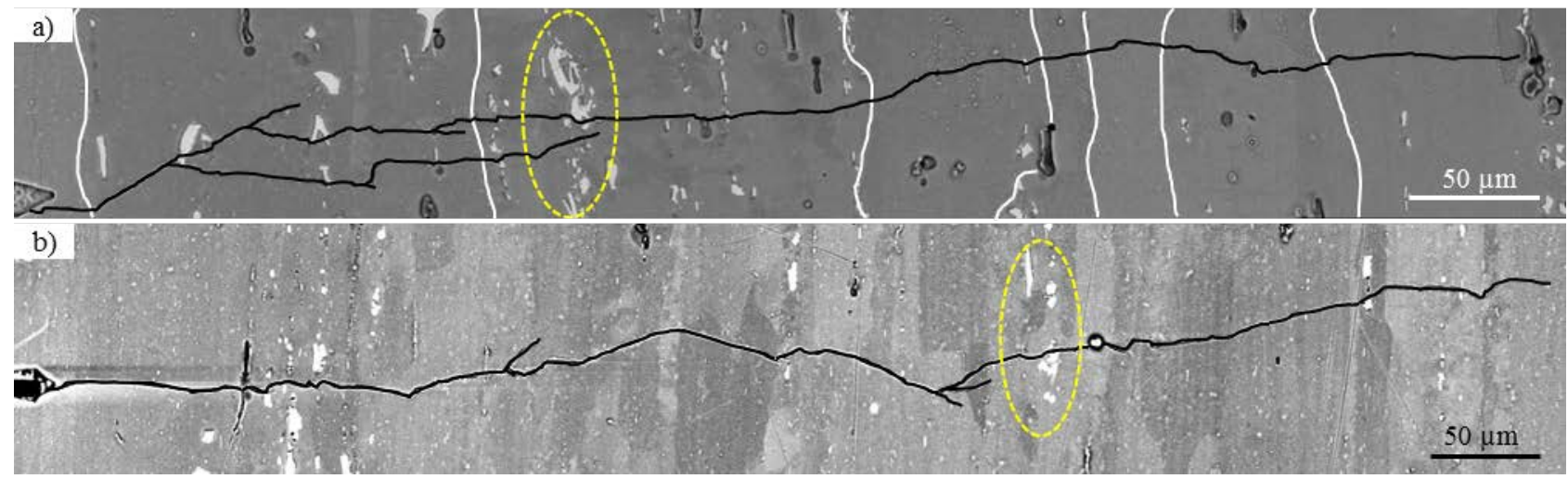

Figure 7. a) Crack path of alloy EN AW 6082 oa at $\Delta \mathrm{K}=1.4 \mu \mathrm{m}$ (grain boundaries in white) b) Crack path of alloy EN AW 5083 at $\Delta \mathrm{K}=2.1 \mathrm{MPa} \sqrt{\mathrm{m}}$.

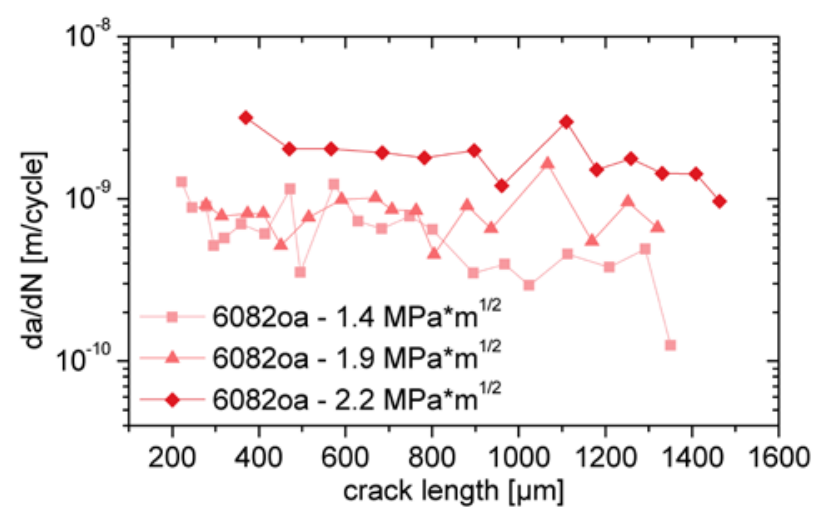

Figure 6. Crack growth rates vs. crack length at constant $\Delta \mathrm{K}$ values for alloy EN AW 6082 in the overaged condition.

\subsection{Correlation between microstructure and fatigue crack growth rate}

By investigating the crack path on the surface of the samples, it becomes apparent that the decelerations of the crack growth rate are mainly caused by microstructural features. Especially the primary precipitates in alloy EN AW 6082 have a great influence on the long crack propagation in the VHCF regime.

Figure 7a shows the crack path for alloy EN AW $6082 \mathrm{oa}$ at $1.4 \mathrm{MPa} \sqrt{\mathrm{m}}$, corresponding to the $\mathrm{da} / \mathrm{dN}$ vs. a curve shown in Figure 4. In this curve there are some decelerations of the crack growth rate visible, for example the decrease at a crack length of about $500 \mu \mathrm{m}$. This decrease is mainly caused by the right crack tip, which reaches at this point a cluster auf Fe-based primary precipitates (Figure 7a, yellow ellipse). At this point the precipitates act as a microstructural barrier. The crack growth rate decreases also slightly at the end of the test. This is also caused by primary precipitates (as can be seen in Figure 7a), but in this case by a large $\mathrm{Mg}_{2} \mathrm{Si}$ precipitate (as was determined by EDS analysis). The right crack tip stops entirely at this point. The further slight decrease of the crack growth rate is caused by crack growth measurable on the left side of the FIB notch. As is was described earlier the crack growth curves are considering the overall crack propagation. All in all, it can be determined that both types of precipitates act as microstructural barriers in EN AW 6082.
Similar barrier effects can be seen for the peak-aged condition at $1.5 \mathrm{MPa} \sqrt{\mathrm{m}}$ (see Figure 8 and corresponding curve in Figure 4). The crack growth rate decreases after $400 \mu \mathrm{m}$, caused by a large cluster of Fe-based primary precipitates. After passing these precipitates the crack growth rate increases again.

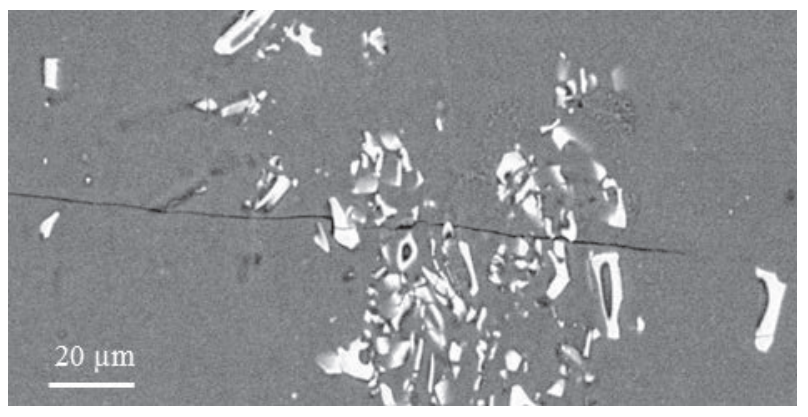

Figure 8. Crack path detail of alloy EN AW 6082 pa at $\Delta \mathrm{K}=1.5 \mathrm{MPa} \sqrt{\mathrm{m}}$.

In EN AW 6082 grain boundaries seem not to have such a great influence on the crack growth as the primary precipitates. An example for their minor influence can be found in the overaged material (see Figure 9). After a crack growth of about $140 \mu \mathrm{m}$ the crack growth rate decelerates. At this point, there is no obvious primary precipitate in the course of the crack, which could cause such a decrease, while a grain boundary can be detected at this point instead. However, the other grain boundaries do not have such a pronounced effect. Which role the orientation of the grain boundary relative to the crack path and the orientation of adjacent grains may possibly play, regarding the function as a microstructural barrier is still under investigation. In addition, the barrier function of the grain boundaries may also be affected by precipitates, because grain boundaries are known as preferred sites for precipitates [12]. 

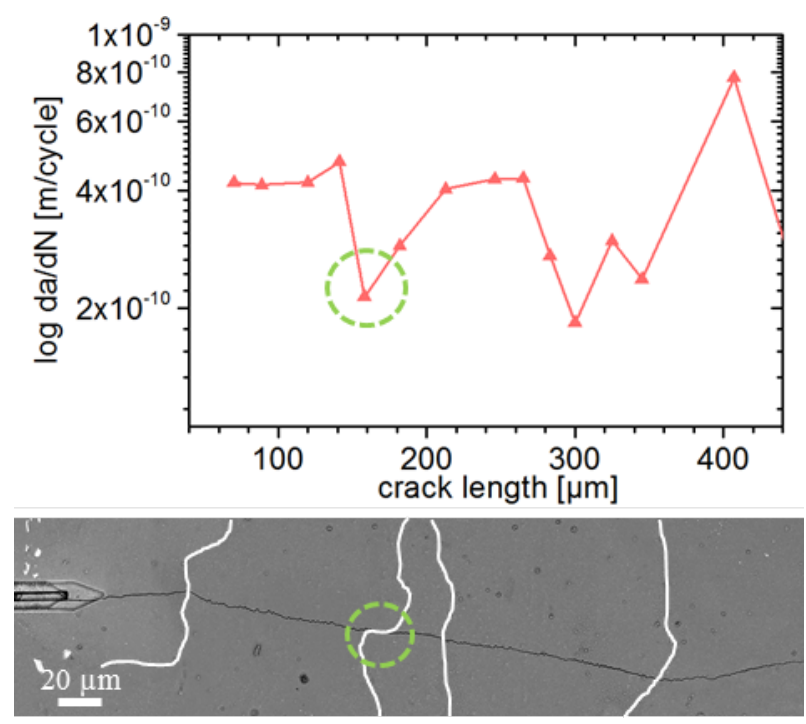

Figure 9. Crack growth rate (right to the FIB notch) for the overaged condition at $\Delta \mathrm{K}=1.9 \mathrm{MPa} \sqrt{\mathrm{m}}$ with corresponding SEM image (grain boundaries in white).

Figure $7 \mathrm{~b}$ shows the crack path of alloy EN AW 5083 at $2.1 \mathrm{MPa} \sqrt{\mathrm{m}}$ (corresponding curve in Figure 5). Obvious local minima were not visible in the da/dN vs. a curve, which can be correlated to only few primary precipitates in front of the crack tip in this test. While regarding only the right crack tip concerning the crack growth rate, there was a drop of the crack growth rate below $10^{-10} \mathrm{~m} /$ cycle measurable at a crack length of about $430 \mu \mathrm{m}$. This can be attributed to the Fe-based precipitate (Figure 7b, yellow ellipse). Furthermore, there are some kinks visible in the course of the crack, which can be associated to passing grain boundaries. When the crack path changes its growth direction this leads also to a deceleration in crack growth rate. Because of the smaller average grain size, this deceleration is not clearly visible in the curve but leads to a smaller average crack growth rate. Figure 10 shows an electron backscatter diffraction (EBSD) analysis of the microstructure surrounding the crack path at $1.7 \mathrm{MPa} \sqrt{\mathrm{m}}_{\mathrm{m}}$ for alloy EN AW 5083. The end of the crack path, where more of the smaller grains are visible, corresponds to the decreasing crack growth rate (see Figure 4). Hence, the barrier effect of the grain boundaries became more effective at the end of the crack path observed in Figure 10. Determining the slip systems with the highest Schmid factor for this particular microstructural detail could show that the crack propagated sometimes in a shear-controlled manner (indicated by white arrows in Figure 10) rather than in mode-I, as is normally typical for long fatigue cracks. Some regions of shear-controlled crack propagation could be found for alloy EN AW 6082 as well, but rarely.

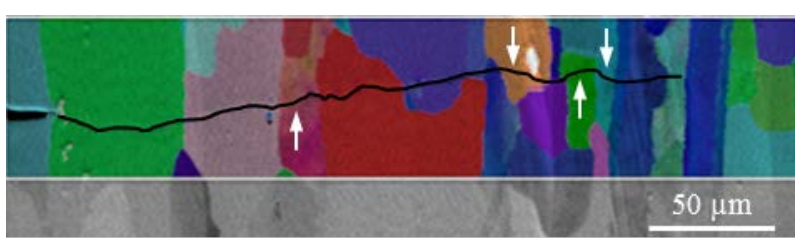

Figure 10. Crack path of alloy EN AW 5083 at $1.7 \mathrm{MPa} \sqrt{\mathrm{m}}$ with overlaying EBSD analysis.

\subsection{Fracture surfaces}

Figure 11 shows the fracture surfaces for the peak-aged and the overaged material. The semi-elliptical shape of the fracture surface, which is characteristic for surface cracks, is clearly visible. Only the ratio of crack length to depth $(\mathrm{a} / \mathrm{c})$ differs between the two samples. Alloy EN AW 6082 in the pa condition has a ratio of 0.67 , whereas the overaged condition has a ratio of 0.78 . Reason for this is supposed to be the higher $\Delta \mathrm{K}$ value compared to the peak-aged condition. It can therefore be reasoned that the crack propagation at the surface is representative for the overall crack growth. The crack propagation on the surface, as well as the propagation into the material are adapting qualitatively to the different $\Delta \mathrm{K}$ values.
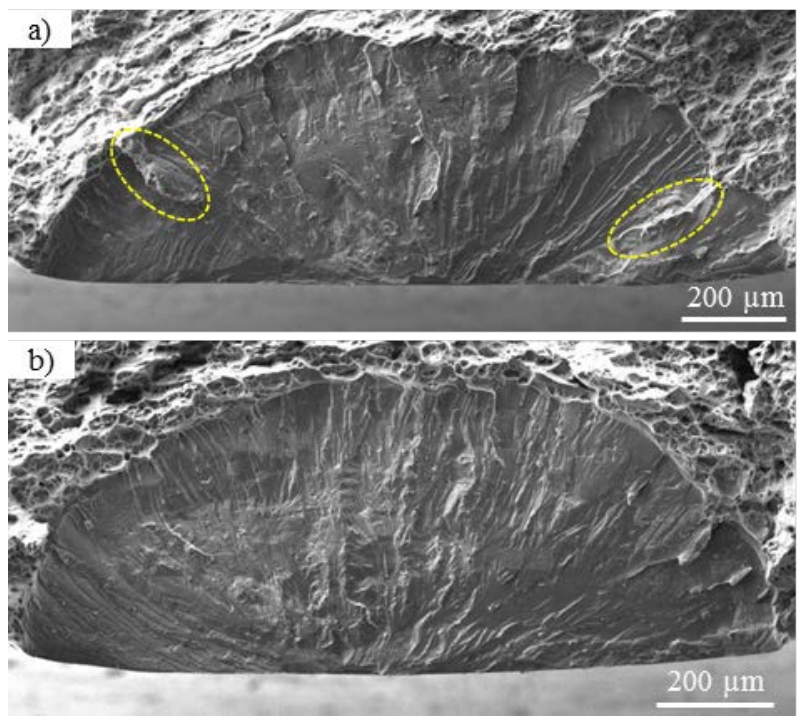

Figure 11. Fracture surfaces for different $\Delta \mathrm{K}$ values a) EN AW 6082 pa at $1.7 \mathrm{MPa} \sqrt{\mathrm{m}}$ b) EN AW 6082 oa at $1.9 \mathrm{MPa} \vee \mathrm{m}$.

The pronounced influence of the microstructure is also reflected by the fracture surfaces, as can be seen e.g. by the outer line of the fatigue fracture surface. For the peak-aged material there are some irregularities of the semi-elliptical shape which extend as "white lines" into the fracture surface. These "white lines" are ductile parts of the fracture surface, as is depicted in Figure 12. It is assumed that the crack front has been pinned at these sites. This feature can be found on the overaged fracture surface as well but is not as pronounced because of the higher $\Delta \mathrm{K}$ value. By comparing the fracture surfaces at similar $\Delta \mathrm{K}$ values the pinning is more pronounced in the overaged material. This has been also investigated by Stein et al. using flat samples [8]. The pinning effect is 
caused by primary precipitates, which however do not differ in alloy EN AW 6082 in both conditions. The reason for the higher pinning effect might be based on the coarsening of the secondary precipitates, which requires still further investigations.
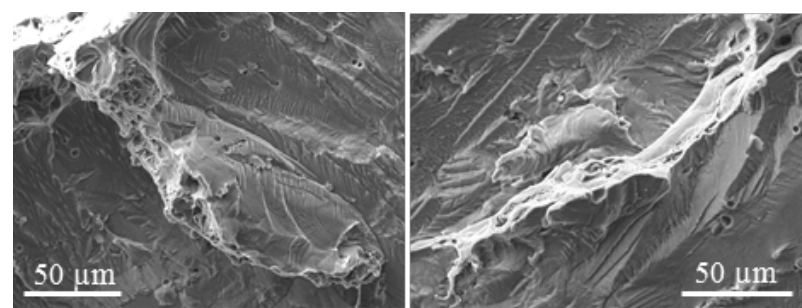

Figure 12. Detailed view of the fracture surface of Figure 11a (yellow ellipses).

Figure 13 shows the fracture surface of alloy EN AW 5083 at $2.1 \mathrm{MPa} \sqrt{\mathrm{m}}$. The fracture surface itself has a much more ductile character than the ones of alloy EN AW 6082. It is assumed that the higher plastic fraction is influenced by a different size of the plastic zone in front of the crack tip, which might have caused already the lower crack propagation rate (see section 3.2). It is also apparent that the crack depth compared to the crack front is quite large; in detail the sample has a depth to length ratio of about 0.93 .

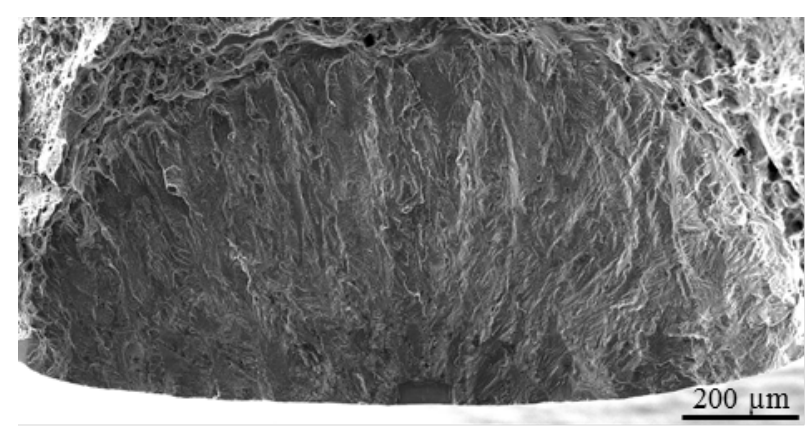

Figure 13. Fracture surface of alloy EN AW 5083 at $\Delta \mathrm{K}=2.1 \mathrm{MPa} \sqrt{\mathrm{m}}$.

\section{Conclusion}

The present research had the aim to experimentally investigate the long crack growth behaviour for two different aluminium alloys near the threshold regime and therefore at very small load amplitudes. The experiments have shown that the microstructure has a barrier function on the fatigue crack propagation for all three investigated material conditions in this region. For the fatigue crack growth behaviour of the two heat treatment conditions of alloy EN AW 6082 no significant differences could be observed. The primary precipitates, especially the Febased ones, have the strongest influence on the crack growth. Grain boundaries can decelerate the crack growth only in very rare occasion, while the role of the secondary precipitates is still under investigation. While analysing the fracture surfaces it seems that the primary precipitates have a greater pinning effect in the overaged condition. For alloy EN AW 5083 a smaller average crack growth rate can be attributed to the smaller grain size and the increasing barrier function of grain boundaries. Primary precipitates are mainly responsible for local changes in the crack growth rate, as was observed for EN AW 6082.

\section{Acknowledgement}

The authors would like to thank the German Research Foundation (DFG) for financial support.

\section{References}

[1] H.-J. Christ, M. Zimmermann. Proceedings of the $7^{\text {th }}$ International Conference on Very High Cycle Fatigue. Siegener Werkstoffkundliche Berichte (2017)

[2] C. Berger, B. Pyttel, D. Schwerdt. Mat.-wiss. u. Werkstofftech. 39 (2008) 769-776

[3] H. Mughrabi. Fat. Fract. Engng. Mater. Struct. 22 (1999) 633-641

[4] S. Stanzl-Tschegg. Int. J. of Fatigue 60 (2014) 2-17

[5] ASTM E 647-11. Standard test method for measurement of fatigue crack growth rates. Philadelphia: American Society for Testing and Materials (ASTM); 2011.

[6] J. Bach, H.W. Höppel, M. Prell, M. Göken. Int. J. of Fatigue 60 (2014) 23-27

[7] E. Zaiken, R. O. Ritchie. Mat. Sci. \& Eng. 70 (1985) 151160

[8] M. Wicke, A. Brückner-Foit, T. Kirsten, M. Zimmermann, F. Bülbül, H.-J. Christ. Proc. Struct. Int. 7 (2017) 235-241

[9] B. Tabernig, R. Pippan. Eng. Fract. Mech. 69 (2002) 899907

[10] T. Stein, M. Wicke, A. Brückner-Foit, T. Kirsten, M. Zimmermann, F. Bülbül, H.-J. Christ. J. Mat. Res. 23 (2017) 1-8

[11] U. Zerbst, M. Vormwald, R. Pippan, H.-P. Gänser, C. Sarrazin-Baudoux, M. Madia. Eng. Fract. Mech. 153 (2016) 190-243

[12] J. W. Martin. Precipitation Hardening - Second Edition. Butterworth-Heinemann (1998) 